\title{
Serum carnitine, triglyceride and cholesterol profiles in Korean neonates
}

\author{
Eun-Mi Ahn ${ }^{1}$, Soo-Chul $\mathrm{Cho}^{2}$, Myoungsook Lee ${ }^{3}$ and Youn-Soo Cha ${ }^{1 *}$ \\ ${ }^{1}$ Department of Food Science and Human Nutrition and Research Institute of Human Ecology, Chonbuk National University, \\ Jeonju, Jeonbuk, 561-756, Korea \\ ${ }^{2}$ Department of Pediatrics, Chonbuk National University Medical School, Jeonju, Jeonbuk, 561-712, Korea \\ ${ }^{3}$ Department of Food and Nutrition, Sungshin Women's University, Seoul, Korea
}

(Received 20 May 2006 - Revised 3 February 2007 - Accepted 9 February 2007)

\begin{abstract}
This study evaluated carnitine and lipid status of fifty Korean newborns. Each subject was assigned to two groups: one according to body weight at birth and the other according to gestational age. Serum total, HDL- and LDL-cholesterol were significantly lower and triacylglycerols were significantly higher, by $14 \%$, in the low birth weight infant (LBWI, 1310-2490 g) group compared with the normal birth weight infant (NBWI, 2570-4420 g) group. Neither birth weight nor gestational age affected serum total carnitine concentrations. However, serum ASAC (acid-soluble acylcarnitine) concentrations were $43 \%$ higher $(P<0.001)$ in the LBWI group compared with the NBWI group, and approximately twice as high $(P<0.05)$ in the 28-32 gestational age group compared with the other gestational age groups. NEC (non-esterified acyl carnitine) fractions were significantly higher in the NBWI and 28-32 week groups $(P<0.001$ and $P<0.05)$; consequently serum acyl/NEC carnitine ratios were four times higher in the LBWI group compared with the NBWI group and 2-3 times higher in the 25-32 week age group compared with the more advanced gestational age groups. Urinary carnitine excretion, including the NEC fraction and total carnitine, was significantly higher $(P<0 \cdot 001)$ for LBWI than for NBWI. By gestational age, NEC excretion of the 28-32 week group was significantly $(P<0 \cdot 05)$ higher than that of the other two groups, but total carnitine excretion was not different among the groups. This study demonstrated that Korean immature and preterm newborns have higher serum triacylglycerol concentrations but lower carnitine status than NBWI. Therefore, the lower carnitine status and moderately higher triacylglycerols may suggest that LBWI in Korea might be at risk for poor carnitine status and decreased capacity to utilise fatty acids for energy.
\end{abstract}

Carnitine: Triglyceride: Cholesterol: Low birth weight infant

The growth and development of adipose tissue in late gestation is primarily in preparation for life after birth (Stephenson et al. 2001). A major source of energy for the fetus is glucose (Warshaw \& Curry, 1980), but immediately after birth NEFA are mobilised from adipose tissue stores (Bieber et al. 1973). A rapid increase in the activity of carnitine palmitoyltransferase I and II, and a rise in the capacity to oxidise fatty acids are seen in liver and heart, reflecting prompt adaptation to lipid as a preferred metabolic fuel for the newborn (Roschinger et al. 2000).

Carnitine (L-3-hydroxy-4- $N, N, N$-trimethylaminobutyrate) is an essential metabolic mediator, which has a number of indispensable roles in intermediary metabolism (Vaz \& Wanders, 2002). It has important roles in fatty acid metabolism, as well as in carbohydrate oxidation in cardiac myocytes, including facilitating $\beta$-oxidation by transporting activated fatty acids into the mitochondrial matrix (Kelly, 1998), and the enhancement of the metabolic flux in the tricarboxylic acid cycle by sparing free coenzyme A (CoA) (Neeley \& Morgan, 1974).

In humans, the carnitine supply is derived in part from food and in part by endogenous synthesis from lysine and methionine
(Koumantakis et al. 2003). Exogenous L-carnitine is used clinically for the treatment of carnitine deficiency disorders and a range of other conditions (Evans \& Fornasini, 2003).

During the first hours after birth, the mitochondria, particularly in the heart, use fatty acids as the major source of energy. However, if fatty acid oxidation is impaired, increased use of glucose can result in hypoglycaemia which may cause cardiomyopathy (Guertl et al. 2000). Carnitine can, therefore, be regarded as essential for long-chain fatty acid metabolism and neonatal growth and development. Newborns, and especially premature newborns, have a very limited capacity for carnitine biosynthesis (Borum \& Bennett, 1986). Furthermore, renal tubular reabsorption of carnitine is less efficient and correlates with gestational age (GA) in neonates (Zamora et al. 1995), although it is still in a near normal range. The primary determinant of carnitine status in neonates appears to be carnitine stores at birth resulting from the transfer of maternal carnitine to the fetus (Koumantakis et al. 1997), and carnitine in the mother's milk at birth must be sufficient to maintain carnitine status until biosynthesis is developed after a few weeks. In a previous study of neonatal

Abbreviations: AIAC, acid-insoluble acyl carnitine; ASAC, acid-soluble acylcarnitine; GA, gestational age; LBWI, low birth weight infant; NBWI, normal birth weight infant; NEC, non-esterified acyl carnitine; TCNE, total carnitine.

* Corresponding author: Dr Youn-Soo Cha, fax +82-63-270-3854, email Cha8@chonbuk.ac.kr 
carnitine status (Meyburg et al. 2002), an immature baby was reported to be slower than normal neonates in the recovery of carnitine levels at each stage of development.

On the basis of this, carnitine is being added as an essential nutrient to total paenteral nutrition and to the diets of immature and normal neonates in advanced nations of Western Europe (Schmidt-Sommerfeld et al. 1983). Few investigators, however, have evaluated the carnitine status of immature newborns in their particular domestic region or in populations in which the traditional diets are low in carnitine.

Korean diets are typically lower in carnitine than Western diets (Lee et al. 2002), but there have been few studies of carnitine status or dietary intake in the Korean population. In our previous study (Cho \& Cha, 2005), we found that low carnitine intake could result in marginal carnitine status of Korean mothers, which could in turn exacerbate the impaired carnitine status of premature infants. Therefore, this study investigated the effects of low birth weight and early GA on parameters of lipid metabolism, including serum lipid profiles and serum and urinary carnitine, in Korean newborn infants.

\section{Materials and methods}

\section{Subjects and experimental design}

This study was performed on fifty newborns, thirty-two boys and eighteen girls less than 1 week old, born in the obstetrics units and neonatal intensive care unit (NICU) at Chonbuk National University Hospital in Jeonju, Korea. Non-Korean newborns having different birth weight distributions were excluded due to racial differences. Infants with severe malformations, metabolic diseases, prenatal asphyxia or proven bacterial infection were also excluded from the study. Each newborn was categorised both by body weight and by GA immediately after birth. There were two groups according to body weight. The low birth weight infant (LBWI) group was composed of twenty-five under $2500 \mathrm{~g}$ body weight newborns, and the normal birth weight infant (NBWI) group had twenty-five over $2500 \mathrm{~g}$ body weight newborns.

A sample size of twenty in each group was determined to be sufficient to detect a clinically important difference of $15 \mu \mathrm{mol} / \mathrm{l}$ in serum total carnitine between LBWI and NBWI, the primary outcome, assuming a standard deviation of $17 \mu \mathrm{mol} / \mathrm{l}$ (as estimated from previous data) using a twotailed $t$ test of the difference between means, a power of $80 \%$ and a significance level of $5 \%$. The number of subjects was increased to twenty-five to allow for the unexpected possibility of subjects dropping out or being eliminated from the study. Power tests were also conducted to ensure adequacy of secondary outcomes of serum non-esterified acyl carnitine (NEC) and triacylglycerols, and urinary total carnitine.

The infants were also divided into three groups by GA: $28-$ 32 week group, 33-36 week group and 37-40 week group. All infants reached the final trimester of a normal full-term delivery (28-40 weeks) by WHO's method of classification (World Health Organization, 1972) and were divided into groups according to a modified Yerushalmy's classification (Yerushalmy, 1972). Sample collection and general data records were obtained from September 2003 to October 2004.

Growth parameters were documented at birth, on the day of study entry and $7 \mathrm{~d}$ after study entry. This study was approved by the Chonbuk National University Ethic Board of Clinical Experiments, and informed consent was obtained from the parents and attending physicians.

\section{Blood and urine sample collections}

Samples were collected from each infant at birth and at $7 \mathrm{~d}$ of age. Blood samples were obtained by venepuncture, transferred into tubes, immediately allowed to coagulate on ice and centrifuged in a refrigerated centrifuge for $15 \mathrm{~min}$ at 3500 r.p.m. to obtain serum within an hour. In addition, urine samples from each subject were collected into plastic containers containing toluene as a preservative. The serum was coded and immediately separated and frozen, as were untreated urine samples, at $-80^{\circ} \mathrm{C}$ until analysis.

\section{Serum lipids and urinary creatinine assay}

Serum triacylglycerols, HDL-cholesterol and total cholesterol were estimated by an enzymatic colorimetric method using a commercial assay kit (Asan Pharm. Co., Seoul Korea). LDL-cholesterol was calculated using the equation of Friedwal et al. (1972) (LDL cholesterol = total cholesterol HDL cholesterol - triacylglycerols/5). Urinary creatinine levels were assayed by the Jaffe method using a commercial kit (Asan Pharm. Co., Seoul, Korea).

\section{Carnitine assay}

Carnitines in serum and urine were assayed using the radioisotopic method of Cederblad \& Lindstedt (1972) as modified by Sachan et al. (1984). Internal isotope standards for each carnitine fraction were added to correct sample data. The coefficient of variation was $2.44-3.43 \%$ within and between assay. A $100 \mu \mathrm{l}$ sample was hydrolysed with $200 \mu \mathrm{l}$ of $0.5 \mathrm{M}-\mathrm{KOH}$ and then centrifuged at $1500 \mathrm{~g}$ for $10 \mathrm{~min}$. Acidsoluble acyl carnitine (ASAC) and NEC were determined in the supernatant, and acid-insoluble acyl carnitine (AIAC) was determined in the pellet. A $150 \mu$ l aliquot of the supernatant was neutralized with $1 \mathrm{M}-\mathrm{KHCO}_{3}$ for measurement of NEC. In the ASAC assay, $100 \mu$ l of supernatant was hydrolysed with $0.5 \mathrm{M}-\mathrm{KOH}$ and neutralized with PCA/MOPS-II solution. The pellet containing AIAC was washed with $0.6 \mathrm{M}-\mathrm{PCA}$ and drained. It was then hydrolysed in $0.5 \mathrm{M}-\mathrm{KOH}$ for $60 \mathrm{~min}$ in a waterbath at $60^{\circ} \mathrm{C}$, and neutralised with PCA/MOPS-I. The reaction mixture (1 M-MOPS buffer, $0 \cdot 1$ M-potassium ethyleneglycoltetra-acetate, $0 \cdot 1$ M-sodium tetrathionate and $0 \cdot 1 \mathrm{~mm}-\left[1-\mathrm{C}^{14}\right]$ acetyl-CoA solution (Amersham, Little Chalfont, Buckinghamshire, UK)) was then added, diluted with water to $100 \mu \mathrm{l}$, and incubated with carnitine acetyl transferase (Sigma Chemical Co., St Louis, MO, USA) in a water bath at $37^{\circ} \mathrm{C}$ for $30 \mathrm{~min}$. At the end of the incubation time, $200 \mu$ l of incubation mixture was transferred onto an ion exchange mini-column. After the sample had been absorbed, eluted with two $500 \mu \mathrm{l}$ portions of water and then further diluted with water, it was then transferred to a $20 \mathrm{ml}$ scintillation vial and counted with liquid scintillation fluid. The radioactivity of each sample was determined in a Beckman LS-3801 liquid scintillation counter (Beckman Instruments, Palo Alto, CA, USA). 


\section{Statistical analysis}

Data were analysed using the SPSS 12.0.1 package. Student's $t$ test was used for testing significance of differences between the two groups of unpaired samples according to birth weights. Significant differences among the three groups according to GA were analysed by ANOVA and Duncan's multiple range test. The level of significance for all the tests was set at $P<0 \cdot 05$. Pearson's correlation coefficient and regression coefficient were used to determine correlations between continuous variables.

\section{Results}

\section{General characteristics of subjects}

General characteristics and growth parameters of the subjects are shown in Table 1. Mean GA at birth was 255.79 (SD 21.32)d. Mean Apgar scores at 1 and 5 min were 7.45 (SD 1.48) and 8.69 (SD 1.69), respectively. Newborns with birth weights under $2500 \mathrm{~g}$ (LBWI) had significantly lower Apgar indexes at 1 and $5 \mathrm{~min}$, and lower GA at birth than those in the over $2500 \mathrm{~g}$ birth weight group (NBWI). Mean height and body weight immediately after birth were $46 \cdot 21($ SD $3 \cdot 86) \mathrm{cm}$ and 2650 (SD 766.01) g. Mean head and chest circumferences were 32.76 (SD 2.28) and 30.00 (SD 3.63) cm, respectively. All growth parameters in this study were significantly higher in the NBWI group than in the LBWI group.

Table 1 shows growth parameters in the subjects based upon GA. Apgar scores at 1 and 5 min were not different between the 33-36 week and 37-40 week GA newborns. However, the score for the 28-32 week GA babies was significantly lower than for the 37-40 week group. Newborns with a GA of 28-32 weeks had lower Apgar scores, heights, weights, and head and chest circumferences than the others.

\section{Serum lipid concentrations}

Triacylglycerols were significantly higher in the LBWI group than in the NBWI group, but total cholesterol, HDLcholesterol and LDL-cholesterol concentrations were significantly higher in the NBWI group than in the LBWI group (Table 2).

Lipid concentrations according to GA groups are shown in Table 2. Triacylglycerol concentrations in the 37-40 week group were significantly lower than in the 33-36 week group. Total cholesterol, HDL-cholesterol and LDL-cholesterol concentrations were significantly higher in the 37-40 week group than in the earlier GA groups. There were no differences in lipid profiles between the 28-32 week and 33-36 week groups.

\section{Serum carnitine concentrations}

Serum carnitine concentrations are shown in Table 2. NEC concentrations were significantly higher in the NBWI group than in the LBWI group. On the one hand, ASAC concentrations were significantly higher in the LBWI group than in the NBWI group and there were no differences in AIAC and total carnitine (TCNE) concentrations. On the other hand, the acylcarnitine/ NEC ratio was significantly higher in the LBWI group than in the NBWI group. The NEC/TCNE ratio was significantly higher in the NBWI group than in the LBWI group.

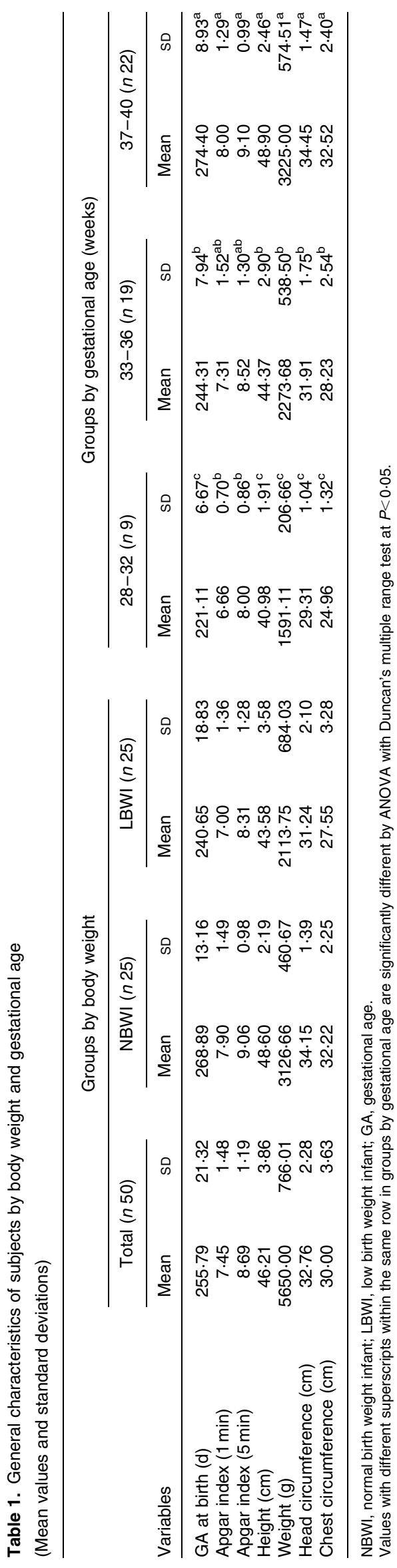


Table 2. Lipid and carnitine concentrations of subjects by body weight and gestational age (Mean values and standard deviations)

\begin{tabular}{|c|c|c|c|c|c|c|c|c|c|c|}
\hline \multirow[b]{3}{*}{ Variables } & \multicolumn{4}{|c|}{ Groups by body weight } & \multicolumn{6}{|c|}{ Groups by gestational age (weeks) } \\
\hline & \multicolumn{2}{|c|}{ NBWI (n 25) } & \multicolumn{2}{|c|}{ LBWI $(n$ 25) } & \multicolumn{2}{|c|}{$28-32(n 9)$} & \multicolumn{2}{|c|}{$33-36(n 19)$} & \multicolumn{2}{|c|}{$37-40$ ( $n$ 22) } \\
\hline & Mean & SD & Mean & SD & Mean & SD & Mean & SD & Mean & SD \\
\hline \multicolumn{11}{|l|}{ Serum lipids (mg/dl) } \\
\hline Triacylglycerols & 55.04 & 15.43 & 62.49 & $20 \cdot 65^{\star}$ & 63.80 & $26 \cdot 93^{\mathrm{a}, \mathrm{b}}$ & 68.99 & $17 \cdot 03^{\mathrm{a}}$ & 49.66 & $13 \cdot 92^{\mathrm{b}}$ \\
\hline Total cholesterol & 84.82 & $18 \cdot 60$ & $62 \cdot 13$ & $16 \cdot 50^{\star \star *}$ & $56 \cdot 38$ & $20 \cdot 41^{\mathrm{b}}$ & 68.33 & $20 \cdot 25^{\mathrm{b}}$ & 87.22 & $21 \cdot 72^{\mathrm{a}}$ \\
\hline HDL-cholesterol & 28.92 & $6 \cdot 61$ & 19.80 & $3 \cdot 80^{\star \star *}$ & 18.08 & $5 \cdot 58^{\mathrm{b}}$ & 22.14 & $5 \cdot 33^{b}$ & 28.42 & $6 \cdot 77^{\mathrm{a}}$ \\
\hline LDL-cholesterol & 44.89 & $18 \cdot 84$ & 29.83 & $13 \cdot 33^{\star \star \star}$ & $25 \cdot 54$ & $13.59^{b}$ & $32 \cdot 39$ & $18 \cdot 31^{\mathrm{b}}$ & $48 \cdot 86$ & $19 \cdot 50^{\mathrm{a}}$ \\
\hline \multicolumn{11}{|l|}{ Serum carnitine $(\mu \mathrm{mol} / \mathrm{l})$} \\
\hline NEC & 22.99 & 8.98 & 13.08 & $7 \cdot 76^{\star \star \star}$ & $10 \cdot 79$ & $7 \cdot 4^{\mathrm{b}}$ & 17.67 & $7 \cdot 82^{\mathrm{a}}$ & $22 \cdot 1$ & $7.96^{\mathrm{a}}$ \\
\hline ASAC & 14.92 & $13 \cdot 33$ & $25 \cdot 67$ & $16 \cdot 29^{\star \star \star}$ & $31 \cdot 17$ & $5 \cdot 57^{\mathrm{a}}$ & $20 \cdot 29$ & $18 \cdot 57^{b}$ & $15 \cdot 29$ & $8.25^{\mathrm{b}}$ \\
\hline AIAC & $5 \cdot 2$ & $3 \cdot 2$ & 4.28 & $2 \cdot 83$ & 4.61 & 3.9 & 4.37 & 2.32 & 6.72 & 3.24 \\
\hline TCNE & 42.08 & $13 \cdot 14$ & 43.04 & $16 \cdot 66$ & 46.58 & 8.72 & $42 \cdot 34$ & $18 \cdot 87$ & 44.09 & $12 \cdot 21$ \\
\hline Acyl carnitine/NEC & 0.93 & 0.83 & 3.60 & $3 \cdot 17^{\star \star \star}$ & 4.22 & $2 \cdot 69^{\mathrm{a}}$ & 1.92 & $1.84^{\mathrm{b}}$ & 1.26 & $0.99^{\mathrm{b}}$ \\
\hline NEC/TCNE & 0.58 & 0.22 & 0.32 & $0 \cdot 19^{\star \star \star}$ & 0.22 & $0.12^{b}$ & 0.46 & $0.22^{\mathrm{a}}$ & 0.5 & $0.13^{\mathrm{a}}$ \\
\hline \multicolumn{11}{|c|}{ Urinary carnitine ( $\mu \mathrm{mol} / \mathrm{g}$ creatinine) } \\
\hline NEC & $10 \cdot 28$ & $4 \cdot 21$ & $27 \cdot 88$ & $26 \cdot 54^{\star \star \star}$ & $22 \cdot 7$ & $16 \cdot 82^{\mathrm{a}}$ & $15 \cdot 32$ & $12 \cdot 33^{\mathrm{ab}}$ & $10 \cdot 18$ & $4.49^{b}$ \\
\hline ASAC & 6.68 & 4.08 & 4.23 & 2.06 & $5 \cdot 10$ & 2.86 & 4.73 & 3.80 & $6 \cdot 29$ & $4 \cdot 81$ \\
\hline AIAC & 2.78 & 1.79 & 3.96 & $2 \cdot 80^{\star}$ & 4.45 & 3.38 & 3.75 & $2 \cdot 24$ & $2 \cdot 76$ & 1.96 \\
\hline TNCE & 18.99 & $5 \cdot 72$ & 33.61 & $29 \cdot 15^{\star \star \star}$ & 35.52 & 30.84 & 37.68 & 35.45 & 18.96 & $6 \cdot 86$ \\
\hline
\end{tabular}

NEC concentrations according to GA were significantly higher in the 33-36 week than in the 28-32 week group. There were no differences between the 33-36 and 37-40 week groups. ASAC concentrations were significantly higher in the 28-32 week than 33-36 week group, but there were no differences between the 33-36 week and 37-40 week groups. AIAC and TCNE were not different among the three groups. The acylcarnitine/NEC ratio was significantly higher in the 28-32 week group than in the 33-36 week group, but there were no differences between the 33-36 week and 37-40 week groups. The NEC/TCNE ratio was significantly higher in the 33-36 week group than in the 28-32 week group. However, no differences were observed between the 33-36 week group and 37-40 week group.

\section{Urinary carnitine excretions}

Table 2 shows urinary carnitine excretion of the subjects. The LBWI group had significantly higher NEC, AIAC and TCNE concentrations than the NBWI group. ASAC concentrations were not different among the groups.

NEC concentrations by GA were significantly higher in the 28-32 week group than in the 37-40 week group; the 33-36 week group showed no differences between the 28-32 week and 37-40 week groups. ASAC, AIAC and TCNE were not different among the groups. The 33-36 week group was not significantly different from either the 28-32 week or the 37-40 week group.

\section{Correlations between variables and parameters}

Serum triacylglycerol concentrations after birth were negatively correlated with birth weight $(r-0.655, P<0.05)$ and gestational age $(r-0.516, P<0.05)$. Serum NEC concentrations positively correlated with body weight $(r 0.582, P<0.05)$ and GA $(r 0.571, P<0.05)$. In contrast, serum ASAC were negatively correlated with body weight $(r-0.409, P<0 \cdot 05)$. Urinary NEC excretion was negatively correlated with body weight $(r-0.545, P<0.05)$

\section{Discussion}

It is important to view this study in terms of the newborn's energy metabolic adaptation. The small size and the correspondingly high surface-to-volume ratios make newborns especially prone to heat loss. Prior to birth, the mother maintains the body heat of the infant, but after birth the infant must do so. However, it adapts to this risk by elevating its metabolic rate (Singer, 1998). Likewise, immature (preterm and low birth weight) infants must also make the extrauterine adaptation after birth. However, for them it is a greater challenge than for an infant born at full term and normal birth weight, because the hormones and enzymes controlling intermediary metabolism are not fully developed in preterm neonates (Plides, 1986).

During delivery, plasma concentrations of adrenaline, noradrenaline and glucagon increase rapidly, whereas the insulin concentration declines. The effect of the hormonal changes is to mobilise stored glycogen and fatty acids (Sinha \& Donn, 2006). During the first hour after birth, there is usually a brisk ketogenic response to low blood glucose levels (Rooy \& Hawdon, 2002). Fasting ketosis develops over hours in children, increasing gradually after postprandial nutrients are utilised and tissue glycogen is progressively depleted (Bonnefont et al. 1990). Compared with mature newborns, immature newborns have low ketone body concentrations which vary little during the first postnatal week (Hawdon et al. 1992). During this 'brisk ketogenic response' 
of neonates, fatty acids must be used as an energy source as well as to maintain the fluidity, permeability and conformation of membranes, and as precursors of important bioactive compounds such as the prostacyclins, prostaglandins, thromboxanes and leukotrienes (Haggarty, 2002).

Low birth weight is a marker for nutrient insufficiency at particular stages of gestation, and seems to be associated with persisting changes in cholesterol metabolism (Barker, 1997). In a previous study, triacylglycerols were higher in newborns with intrauterine growth restriction, compared with normally developed newborns (Molina et al. 2000). Kaser et al. (2001) reported that neonates who were small for gestational age had significantly higher triacylglycerol levels than those of appropriate size or large for gestational age. The results in this study are similar to the previous data (Skinner et al. 1983; Molina et al. 2000). Triacylglycerols in the LBWI group were significantly higher than in the NBWI group, and in the 33-36 week group were significantly higher than in the 37-40 week group. Considering the low ketogenic capacity of immature babies (Hawdon, 1999), high triacylglycerols in this situation seem to be related to an increased hypoglycaemic risk of immature babies (Embleton \& Ward Platt, 2003).

A previous study of serum total, HDL- and LDL-cholesterol levels in newborns revealed no significant differences according to the degree of their maturation. There were no differences in total, HDL- and LDL-cholesterol between intrauterine growth-retarded and normally developed newborns (Molina et al. 2000). Skinner et al. (1983) reported that there were no correlations between the composition or concentration of any cord blood lipoprotein fractions and birth weight or gestation. Kaser et al. (2001) reported that birth weight was not the sole determinant of lipoprotein levels in neonates. However, in this study, total, HDL- and LDL-cholesterol levels were significantly higher in the NBWI group than in the LBWI group. Total, HDL- and LDL-cholesterol levels were all significantly elevated in the 37-40 week group compared with the below-36 week groups. The different result in this study, compared with the previous study, seems to be caused by the different GA, birth body weight, sex and standard of 'immaturatity' in the subjects.

Carnitine is present in biological materials in both the nonesterified form (NEC) and as acylcarnitine (Swell \& Bohles, 1995). NEC typically accounts for around $80 \%$ of total carnitine, and serum concentrations lower than $20 \mu \mathrm{mol} / 1$ are considered a marker of 'carnitine deficiency' (Winter et al. 1990). In this study, mean NEC concentrations of NBWI were similar to those reported by other investigators (Campoy et al. 1998), but the LBWI group infants had serum NEC concentrations of 13.08 (SD 7.76). By GA, 28-32 week and 33-36 week group newborns had NEC concentrations of 10.79 (SD 7.40) and 17.60 (SD 7.82), respectively. Therefore, this study indicates that Korean low birth weight or short GA newborns have 'carnitine deficiency'. A low NEC/TCNE ratio has also been considered to be indicative of 'carnitine deficiency'. A normal value is between 0.70 and 0.95 ; values $<0.70$ indicate a fatty acid oxidation defect which can be caused by 'carnitine deficiency' (Largilliere et al. 1995). In a previous study, no newborn infant had NEC/TCNE ratios below 0.70 at the early neonatal periods (Campoy et al. 1998), but in the current study, our mean ratios are under $0 \cdot 70$, which is different from other studies (Rebouche, 1992). The value for the LBWI group was significantly lower than for the NBWI group, and those for the 33-36 and 37-40 week groups were higher than that for the 28-32 week group. However, if we use an NEC/TCNE ratio below 0.70 to define carnitine deficiency, then all the subjects in this study were 'carnitine deficient' and LBWI and the 28-32 week newborns had significantly greater deficiency.

In serum, AIAC and ASAC are considered very good markers of the activation of fatty acids (Aggett et al. 1991). Therefore, the intramitochondrial relationship between acyl-CoA and free $\mathrm{CoA}$ is reflected by the extramitochondrial acylcarnitine to NEC ratio, acyl-CoA/CoA $\approx$ acylcarnitine/NEC; a high acylcarnitine/NEC is 'a marker of carnitine insufficiency' (Schmidt-Sommerfield et al. 1983; Winter et al. 1990). Since 1982 , values $>0.40$ are considered abnormal and indicate a low availability of NEC to the cells, thus "carnitine insufficiency' (Böhles et al. 1994). In this study, the acyl carnitine/NEC ratios of all groups were $>0.40$, but were especially higher in the LBWI group compared with the NBWI group. By GA group, the 28-32 week group had significantly higher acylcarnitine fractions than the 33-36 week and 37-40 week groups. It seems that the higher acylcarnitine/NEC ratios in this study are chiefly caused by increased ASAC levels, especially in immature newborns. Thus it seems that a newborn infant, especially an immature one, is born with limited carnitine reserves. The high acylcarnitine/NEC ratio noted in neonates is thought to reflect the increased production of acyl-CoA derivatives, mainly acetylCoA produced by normally enhanced fatty acid oxidation in the newborn period (Warshaw \& Curry, 1980; Girard et al. 1992; Arenas et al. 1998). The association of low birth weight with higher TCNE values may be related to decreased tissue carnitine uptake (Chace et al. 2003). In the current study, however, there were no differences in TCNE concentrations by birth weight or by GA.

The selective excretion of acylcarnitine provides a route for eliminating accumulating intermediates in metabolic disorders (Siliprandi, 1986). Excessive loss of these specific acylcarnitines in the urine results in loss of free carnitine and increases the probability of secondary carnitine deficiency (Pons \& de Vivo, 1995). Urinary excretion of NEC and TCNE fractions was significantly higher in the LBWI group than in the NBWI group. By GA, urinary NEC excretion in the 28-32 week neonates was significantly higher than in the 33-36 week group. By weight group, ASAC excretion was not statistically different between groups, but AIAC excretion was significantly higher in the LBWI group.

In previous studies, immature newborns have been shown to have higher plasma and red blood cell carnitine concentrations at birth than full-term neonates (Borum, 1995). However, in this study, there were no differences in TCNE values between mature and immature newborns, but carnitine fractions were different and markers of 'deficiency' and 'insufficiency' significantly greater for the low birth weight and early gestational groups.

All infants have carnitine stores, well below adult levels, at birth, but preterm infants have much lower stores than do fullterm infants (Shenai \& Borum, 1984). We have previously found that pregnant Korean women have marginal carnitine 
status due to relatively low dietary intake and increased urinary excretion of carnitine (Cho \& Cha, 2005). Low dietary intakes of folate, protein and energy may also contribute to the marginal carnitine status of Korean women of childbearing age (Cha et al. 1998; Lee et al. 2005). This study was based on the premise that compromised carnitine status in Korean mothers might exacerbate low carnitine stores in preterm Korean infants. The high acyl/free serum carnitine in Korean preterm infants suggests that Korean preterm infants may indeed have lower carnitine stores than their counterparts in Western countries. Marginal or insufficient carnitine status is not unique to Korean preterm infants. Muscle tissue begins to accumulate carnitine stores at about the same time as fat stores begin to accumulate, in preparation for the utilisation of lipids as a major energy source after birth (Reichman, 1981; Shenai \& Borum, 1984), and the degree of accumulation is largely a factor of gestational age. The source of carnitine for the fetus is exclusively from the blood supply from the mother, and the transfer of carnitine from the mother is a major determinant of carnitine status of a neonate (Koumantakis et al. 1997). When an infant is born prematurely, there is no further supply of carnitine from the mother and the carnitine biosynthesis enzymes are not yet fully active (Melegh et al. 1996). Consequently, preterm infants have little of their own fat stores to use for energy and less capacity to utilise exogenous fat for energy than do full-term infants. Preterm infants have abnormal circulating lipid-derived metabolites, and little capacity for producing ketone bodies, an important early energy source for the brain. For those reasons and others, an expert panel established by the Life Sciences Research Office (LSRO) and the American Society for Nutritional Sciences recommended to the United States Food and Drug Administration that a minimum of $2.0 \mathrm{mg} / 100 \mathrm{kcal}$ and a maximum of $5.9 \mathrm{mg} / 100 \mathrm{kcal}$ of carnitine be added to carnitine-free preterm infant formulas (American Society of Nutritional Sciences \& Life Sciences Research Office, 2002). These amounts were based on the amounts of carnitine supplied from mother's milk and the amount at which an increased fractional excretion of carnitine is seen in preterm infants. The $5.9 \mathrm{mg} / 100 \mathrm{kcal}$ dose has a history of safe use and it was believed to be well within a safe range by the expert panel. Nevertheless, the conclusions of the expert panel have not been universally accepted due to the lack of a demonstratable effect of carnitine on growth and development in preterm infants (Shortland et al. 1998; Whitfield et al. 2003). Currently, reasonable and informed scientists can reach disparate conclusions about the need for including carnitine in carnitine-free parenteral and enteral infant formulas. However, if such a need does exist, it is reasonable to conclude that Korean preterm infants need carnitine at least as much as, and probably more than, infants from Western countries.

In summary, this study revealed that the immature newborn group had higher serum triacylglycerol concentrations than the mature newborn group, and that there was no difference in TCNE levels between mature and immature newborns. However, the carnitine fractional differences in this study suggest that Korean low birth weight and preterm newborns suffer from compromised carnitine status and abnormal carnitine availability. Therefore, in populations with low carnitine intake, as in Korea, the carnitine status of premature and low birth weight infants may be less than optimal. Therefore, these infants need to be carefully evaluated to ensure that their lipid metabolism is unimpaired by poor carnitine status.

\section{Acknowledgements}

This work was supported by a Korea Research foundation Grant funded by the Korean Government (MOEHED) (the Center for Healthcare Technology development, Chonbuk National University, Jeonju 561-756, Republic of Korea)

\section{References}

Aggett PJ, Haschke F, Heine W, et al. (1991) Comment on the content and composition of lipids in infant formulas ESPGAN Committee on Nutrition. Acta Paediatr Scand 80, 887-896.

American Society of Nutritional Sciences \& Life Sciences Research Office (2002) Nutrient requirements for preterm infants - carnitine. J Nutr 132, 1434s-1437s.

Arenas J, Rubio JC, Martin MA \& Campo Y (1998) Biological roles of L-carnitine in perinatal metabolism. Early Hum Dev 53, S43-S50.

Barker DJP (1997) Fetal nutrition and cardiovascular disease in later life. Br Med Bull 53, 96-108.

Bieber LL, Markwell MAK, Blair M \& Helmrath TA (1973) Studies on the development of carnitine palmitoyl transferase and fatty acid oxidation in liver mitochondria of neonatal pigs. Biochem Biophys Acta 326, 145-154.

Böhles H, Evangeliov A, Bervotes K, Eckert I \& Swell AC (1994) Carnitine esters in metabolic disease. Eur J Pediatr 153, 57-61.

Bonnefont JP, Specola NB, Vassault A, Lombes A, Ogier H, de Klerk JB, Munnich A, Coude M, Paturneau-Jouas M \& Saudubray JM (1990) The fasting test in pediatrics: application to the diagnosis of pathological hypo and hyperketotic state. Eur J Pediatr 150, $80-85$.

Borum (1995) Carnitine in neonatal nutrition. J Child Neurol 10, S25-S31.

Borum PR \& Bennett SG (1986) Carnitine as an essential nutrient. J Am Coll Nutr 5, 177-182.

Campoy C, Bayes R, Peinado JM, Rivero M, Lopez C \& Molina-Font JA (1998) Evaluation of carnitine nutritional status in full-term newborn infants. Early Hum Dev 53, 149-164.

Cederblad G \& Lindstedt S (1972) A method for the determination of carnitine in the picomole range. Clin Chim Acta 37, 235-243.

Cha YS, Jung BM, Kim HR, Ahn CB \& Lim SS (1998) Regular exercise-training affects serum lipid and carnitine profiles in some college students. J Food Sci Nutr 3, 71-76.

Chace DH, Pons R, Chirboga CA, McMahon DJ, Tein I, Naylor Ew \& De Vivo DC (2003) Neonatal blood carnitine concentrations: normative data by electrospray tandam mass spectrometry. Pediatr Res 53, 823-829.

Cho SW \& Cha YS (2005) Pregnancy increases urinary loss of carnitine and reduces plasma carnitine in Korean women. Br J Nutr 93, $685-691$.

Embleton ND \& Ward Platt MP (2003) Management of hypoglycaemia in the newborn. Curr Paediatr 13, 134-139.

Evans AM \& Fornasini G (2003) Pharmacokinetics of L-carnitine. Clin Pharmacokinet 42, 941-967.

Friedwald WT, Lery RI \& Fredrikson DS (1972) Estimation of the concentration of low-density lipoprotein cholesterol in plasma, without use of the preparative ultracentrifuge. Clin Chem 18, 499-502. 
Girard J, Ferre P, Pegorier JP \& Duee PH (1992) Adaptation of glucose and fatty acid metabolism during perinatal period and suckling-weaning transition. Physiol Rev 72, 507-562.

Guertl B, Noehammer C \& Hoefler C (2000) Metabolic cardiomyopathies. Int J Exp Pathol 81, 349-372.

Haggarty P (2002) Placental regulation of fatty acid delivery and its effect on fetal growth - a review. Placenta 23, 28-38.

Hawdon JM (1999) Hypoglycemia and the neonatal brain. Eur $J$ Pediatr 158, S9-S12.

Hawdon JM, Ward Platt MP \& Aynsley-Green A (1992) Patterns of metabolic adaptation for preterm infants in the first neonatal week. Arch Dis Child 67, 357-365.

Kaser S, Ebenbichler CF, Wolf HJ, Sandhofer A, Stanzl U, Ritsch A \& Patsch JR (2001) Lipoprotein profile and cholesteryl ester transfer protein in neonates. Metabolism 50, 723-728.

Kelly GS (1998) L-Carnitine: therapeutic applications of conditionallyessential amino-acid. Altern Med Rev 3, 345-360.

Koumantakis E, Evageliou A, Sifakis S, Matalliotakis I, Relakis K \& Giannakopoulou C (1997) Comparative study of plasma carnitine: determination in the neonate and in normal deliver. Clin Exp Obstet Gynecol 24, 174-177.

Koumantakis E, Sifakis S, Koumantaki Y, Hassan E, Matalliotakis I, Kraemer WJ, Volek JS \& French DN (2003) The effect of L-carnitine L-tartrate supplementation on hormonal responses to resistance exercise and recovery. J Strength Cond Res 17, 455-462.

Largilliere C, Vianey-Saban C, Fontaine M, Bertrand C, Kacet N \& Farriux JP (1995) Mitochondrial very long chain acyl-CoA dehydrogenase deficiency, a new disorder of fatty acid oxidation. Arch Dis Child 73, 103-105.

Lee JI, Lee JA \& Lim HS (2005) Effect of time of initiation and dose of prenatal iron and folic acid supplementation on iron and folate nutriture of Korean women during pregnancy. Am J Clin Nutr 82, 843-849.

Lee YK, Park YO \& Cha YS (2002) Carnitine content of common Korean foods. Nutraceuticals Food 7, 293-298.

Melegh B, Hermann R \& Bock I (1996) Generation of hydroxytrimethyllysine from trimethyllysine limits the carnitine biosynthesis in premature infants. Acta Paediatr 85, 345-350.

Meyburg J, Schulze A, KOhlmueller D, Poschl J, Linderkamp O, Hoffmann GF \& Maytepek E (2002) Acylcarnitine profiles of preterm infants over the first four weeks of life. Pediar Res 52, $720-723$.

Molina M, Casanueva V, Cid X, Ferrada MC, Perez R, Dios G, Reyes M, Venegas H \& Cid L (2000) Lipid profiles in newborns with intrauterine growth retardation. Rev Med Chil 128, 741-748.

Neeley JR \& Morgan HE (1974) Relationship between carbohydrate and lipid metabolism and the energy balance of heart muscle. Annu Rev Physiol 36, 413-454.

Plides RS (1986) Neonatal hyperglycemia. J Pediatr 109, 905-907.

Pons R \& de Vivo DC (1995) Primary and secondary carnitine deficiency syndromes. J Child Neurol 10, S8-S24.

Rebouche CJ (1992) Carnitine function and requirements during life cycle. FASEB J 6, 3379-3386.

Reichman B (1981) Diet, fat accretion, and growth in premature infants. N Engl J Med 305, 1495-1500.
Rooy L \& Hawdon JM (2002) Nutritional factors that affect the postnatal metabolic adaptation of full-term small- and large-for gestational-age infants. Pediartrics 109, E42.

Roschinger W, Muntau AC, Duran M, Dorland L, IJlst L, Ronald JA, Wanders RJ \& Roscher AA (2000) Carnitine-acylcarnitine translocase deficiency: metabolic consequences of impaired mitochondrial carnitine cycle. Clin Chim Acta 298, 55-68.

Sachan DS, Rhew TH \& Ruark RA (1984) Ameliorating effects of carnitine and its precursors on alcohol induced fatty liver. Am J Clin Nutr 39, 738-744.

Schmidt-Sommerfeld E, Penn D \& Wolf H (1983) Carnitine deficiency in premature infants recieving total parental nutrition: effect of L-carnitine supplementation. J Pediatr 102, 931-935.

Shenai JP \& Borum PR (1984) Tissue carnitine reserves of newborn infants. Pediatr Res 18, 679-682.

Shortland GJ, Walter JH, Stroud C, Fleming PJ, Speidel BD \& Marlow N (1998) Randomised controlled trial of L-carnitine as a nutritional supplement in preterm infatnts. Arch Dis Child Fetal Neonatal Ed 78, F185-F188.

Siliprandi N (1986) Transport and function of carnitine: relevance to carnitine-deficient diseases. Ann NY Acad Sci 488, 118-126.

Singer D (1998) Thermometry and calorimetry in the neonate: recent advances in monitoring and research. Thermochim Acta 309, $39-47$.

Sinha SK \& Donn SM (2006) Fetal-to-neonatal maladaptation. Semin Fetal Neonatal Med 11, 166-173.

Skinner ER, Klopper AI, Wilson GR \& Toop KM (1983) The composition and concentration of umbilical cord plasma lipoproteins; their relationship to the birth weight and other clinical factors of the newborn. Clin Chim Acta 135, 219-228.

Stephenson T, Budge H, Mostyn A, Pearce S, Webb R \& Symonds ME (2001) Fetal and neonatal adipose maturation: a primary site of cytokine and cytokine-receptor action. Biochem Soc Trans 29, $80-85$.

Swell AC \& Bohles HJ (1995) Acylcarnitines in intermediary metabolism. Eur J Pediatr 154, 871-877.

Vaz FM \& Wanders RJ (2002) Carnitine biosynthesis in mammals. Biochem J 361, 417-429.

Warshaw JB \& Curry E (1980) Comparison of serum carnitine and ketone body concentrations in breast-fed newborn infants. J Pediatr 97, 122-125.

Whitfield J, Smith T, Sollohb H, Sweetman L \& Roe C (2003) Clinical effects of L-carnitine supplementation on apnea and growth in very low birth weight infants. Pediatrics 111, 477-482.

Winter SC, Zorn EM \& Hugh Vance W (1990) Carnitine deficiency. Lancet 335, 981-982.

World Health Organization (1972) The Prevention of Perinatal Mortality and Morbidity. Public Health Paper 42. Geneva: WHO.

Yerushalmy J (1972) The classification of newborn infants by birth weight and gestational age. J Pediatr 71, 164-172.

Zamora S, Benador N, Lacourt G, Giradin E, Lacourt G \& Giradin E (1995) Renal handling of carnitine in ill preterm and term neonates. J Pediatr 127, 957-958. 